\title{
Políticas públicas de desenvolvimento regional em Mato Grosso do Sul
}

The regional development public policies in Mato Grosso do Sul

\begin{abstract}
The paper's main objective is to organize and analyze the regional development public policies in Mato Grosso do Sul. To do so, we initially carry out a historical tracking of the development policies applied in the state territory, dating back to the Vargas government. Then, we look at recent policies related to "fiscal wars" and National Integration and Development Axes that in MS resulted in the construction of the Ferronorte railroad and the Brazil-Bolivia gas pipeline besides the Tietê-Paraná waterway. The main results that show the development of the state are marked by the implemented public policies.
\end{abstract}

\section{Keywords}

regional development, state planning and economical-territorial formation.

JEL Codes O20, 021, 022.

\author{
Kaully Furiama Santos (1) \\ Fabricio J. Missio (2) \\ (1) Faculdade de Sinop - Fasip \\ (2) Universidade Federal de Minas Gerais
}

\section{Resumo}

O objetivo deste artigo é elencar e analisar as principais politicas públicas de desenvolvimento regional em Mato Grosso do Sul (MS). Inicialmente, realizamos um levantamento histórico das politicas de desenvolvimento aplicadas nesse território, especialmente após o Governo Vargas. Um exemplo é a criação do Território Federal de Ponta Porã e da Colonia Agrícola de Dourados, dentro do contexto da "Marcha para o Oeste". Em seguida, destacamos os planos liderados pela Superintendência de Desenvolvimento da Região Centro Oeste durante o regime militar. Por fim, analisamos as políticas recentes relacionadas à "guerra fiscal" e à política dos Eixos Nacionais de Integração de Desenvolvimento, que no MS apoiaram a construção da Ferronorte, do gasoduto Brasil-Bolivia e da hidrovia Tietê-Paraná. Os principais resultados indicam que o desenvolvimento de MS é marcado pelas políticas públicas implementadas.

\section{Palavras-chave}

desenvolvimento regional, planejamento estatal e formação econômico-territorial.

Códigos JEL O20, 021, 022 . 


\section{Introdução}

A distribuição desigual do crescimento econômico passou a ser analisada teórica e empiricamente a partir do começo do século XIX. ${ }^{1}$ As primeiras teorias desenvolvidas, chamadas de teorias da localização (escola alemã), analisaram os aspectos da economia regional sob o ponto de vista das firmas (Von Thunen, 1826; Weber, 1909; Losch, 1940; Isard, 1956). Essas teorias identificavam como causas da concentração espacial as próprias características das unidades econômicas (firmas), como o tamanho e os custos de transporte envolvidos na produção.

A partir dos anos de 1950, no contexto do pós-segunda guerra, novas abordagens passaram a enfatizar aspectos das desigualdades regionais até então "negligenciadas" pela escola alemã, com modelos analíticos que enfatizavam a presença de dualismos, de disparidades regionais, da polarização da produção, bem como da presença de fatores de aglomeração e de relações inter-regionais. Destacam-se os trabalhos de Perroux, Myrdal e Hirschman, que incorporam mecanismos dinâmicos endógenos e incluíram o papel/ações do "Estado".

No campo prático, por sua vez, as políticas públicas consideradas de desenvolvimento regional surgiram no interstício das duas grandes guerras, dentro do contexto do pós-crise de 1929 e da ascensão do planejamento estatal no desenvolvimento econômico. No Brasil, os modelos teóricos desenvolvidos nos anos de 1950 influenciaram significativamente na elaboração das políticas e planos de desenvolvimento regional (Lima; Simões, 2009; Diniz, 2009; Fochezatto, 2010). Já havia políticas públicas específicas para algumas regiões desde o império, como no combate às secas no Nordeste (Diniz, 2009). Contudo, estas não são consideradas propriamente políticas de desenvolvimento regional, pois atendiam a fins específicos e/ou problemas pontuais, ou seja, não contemplavam diretrizes amplas de diversificação e dinamização da estrutura econômica social nas regiões aplicadas.

No espaço sul-mato-grossense as primeiras ações estatais datam do século XVIII. Essas ações tinham propósitos geopolíticos, que visavam "ga1 Na teoria econômica clássica o elemento "espaço" é pouco abordado, fato esse sustentado pela hipótese de que "no interior da economia nacional, em verdade, não poderia haver motivo para estudos espaciais, em virtude da suposição da perfeita mobilidade dos fatores de produção, dos bens e serviços e das pessoas. Ela conduziria o sistema econômico ao equilíbrio (...)" (Souza, 1981). 
rantir as fronteiras", alinhadas com objetivos econômicos, relacionados à necessidade de se proteger as jazidas e os caminhos de passagens até as minas de Cuiabá, descobertas naquele século, com o movimento das "bandeiras". Nesse caso, fomentou-se a criação de vilas, arraiais e fortes, entre as quais o Forte de Corumbá (1778), o Forte Coimbra (1775) e o Forte de Miranda (1797) (Abreu, 2001). Posteriormente, a partir da primeira metade do século XIX, a pecuária bovina se tornou a principal atividade econômica na região, ocupando tanto as planícies pantaneiras quanto as terras da bacia do Paraná (Queiroz, 2004), seguida da extração de erva-mate nativa (Barcellos, 2014; Missio e Rivas, 2019).

A participação estatal no desenvolvimento do espaço do Sul do Mato Grosso (SMT), ${ }^{2}$ ocorreu de forma mais ativa a partir das políticas de integração do território nacional. Tais políticas estavam voltadas para a implantação das linhas telegráficas, entre 1901 e 1905, e para a expansão dos transportes terrestres, com destaque para a construção da Ferrovia Noroeste do Brasil (finalizada em 1914) ligando Bauru (SP) a Corumbá (MS) (Barcellos, 2014; Le Bourlegat, 2000).

Posteriormente, nos anos de 1930, concomitante ao início do processo de substituição do modelo de desenvolvimento agroexportador pelo modelo urbano-industrial, foi implementado o programa "Marcha para o Oeste". Esse programa tinha por objetivo povoar e desenvolver a região, dotando-a de maior infraestrutura e promovendo o dinamismo das atividades existentes, bem como a diversificação produtiva. Durante esse período foi criada a Fundação Brasil Central (1943) e o projeto da Colônia Agrícola de Dourados, implementada em 1948. O objetivo da colônia agrícola era ocupar a região do extremo sul de Mato Grosso.

Na segunda metade década de 1960 criou-se a Superintendência de Desenvolvimento do Centro-Oeste (SUDECO), em substituição à Fundação Brasil Central, como um órgão específico para o desenvolvimento da região Centro-Oeste. Sob sua tutela foram desenvolvidos programas para o desenvolvimento do atual território de Mato Grosso do Sul (MS), entre os quais os chamados "programas especiais", quais sejam: o Programa de Desenvolvimento dos Cerrados (POLOCENTRO), o Programa de Desenvolvimento do Pantanal (PRODEPAN) e o Programa de Desenvolvimento da Grande Dourados (PRODEGRAN). A superintendência foi extinta em

2 Em referência ao território de Mato Grosso do Sul antes da divisão. 
1990, no contexto de reestruturação do Estado brasileiro, e recriada em 2009 (regulamentada em 2011). Este último período marca a tentativa de retomada das políticas e ações para o desenvolvimento por meio do planejamento público.

Considerando esse contexto, o objetivo deste trabalho é elencar e analisar as principais políticas públicas de desenvolvimento regional em MS, no período compreendido entre o programa "Marcha para o Oeste" e a implementação da política dos Eixos Nacionais de Integração de Desenvolvimento. A escolha do espaço sul-mato-grossense se justifica pela carência de estudos, especialmente quando comparados a outras regiões do Brasil, bem como pela importância relativa que as políticas públicas de desenvolvimento tiveram na formação econômica do Estado, já que os ciclos de acumulação associados à exploração da erva-mate, da pecuária e da madeira, entre outros, tiveram impactos limitados.

O presente artigo contribui ao elucidar aspectos importantes da formação histórica e econômica de MS, que em 2019 completou 40 anos de formação (o desmembramento de MS ocorreu a partir da Lei Complementar $n^{\circ} 31,11$ de outubro de 1977, embora ele tenha sido elevado à categoria de estado pelo presidente Ernesto Geisel em $1^{\circ}$ de janeiro de 1979). O trabalho se insere na literatura que busca compreender a dinâmica regional brasileira e que de certa forma mostra os limites da análise elaborada em importantes estudos de intelectuais (especialmente vinculados às universidades paulistas e à Comissão Econômica para a América Latina) que, em boa medida, aplicaram uniformemente a mesma análise pensada para São Paulo ao restante do Brasil.

Ainda, ao resgatar as principais políticas de desenvolvimento regional, o trabalho contribui também ao elucidar o papel do Estado brasileiro na construção de políticas ativas em prol do desenvolvimento. Em meio à recente "onda" liberal, especialmente em MS, onde esse pensamento fundamentou as candidaturas que saíram amplamente vencedoras nas últimas eleições presidenciais, mostrar que determinados aspectos da construção material e social que permitiram o desenvolvimento dessa unidade federativa foram pensadas e promovidas pelo Estado brasileiro, no nosso entendimento, é de grande relevância no debate atual.

Para cumprir com os objetivos, este artigo encontra-se estruturado em três seções, além desta introdução. A seção 2 identifica e analisa as principais políticas públicas no espaço sul-mato-grossense, a partir do Governo 
Vargas até os anos "áureos" da SUDECO; a seção seguinte discute o período concomitante ao fim dessa superintendência e faz uma análise das principais direções das políticas públicas realizadas desde então. A seção 4 apresenta as considerações finais.

\section{Programas de desenvolvimento regional em Mato Grosso do Sul}

Nos períodos colonial e imperial, o território de MS foi marcado pela incidência das bandeiras, que visavam encontrar ouro e capturar mão de obra (escrava) indígena, além de ampliar a expansão territorial, tendo em vista a disputa com o reino espanhol. Ressalta-se que pelo instrumento do Utis possedetis ficou estabelecido que o Mato Grosso (incluindo o Mato Grosso do Sul) pertenceria à coroa portuguesa. Nesse período, a presença do Estado português ocorreu principalmente a partir da construção de fortes e do deslocamento de tropas "balizando fronteiras e garantindo a posse das terras" (Le Bourlegat, 2000, p. 110).

Em seguida, no período da Primeira República, após a Guerra do Paraguai (1864-1870), a política que merece destaque é o início da construção da Ferrovia Noroeste do Brasil (NOB). De acordo com Queiroz (2011), o principal objetivo da construção da $\mathrm{NOB}$ era político-estratégico. Ainda que existissem relações comerciais entre Mato Grosso (MT) e São Paulo (SP) que pudessem justificar a construção da ferrovia, o montante era insuficiente para justificar tamanho investimento.

Em outras palavras, havia uma relação estreita entre o mercado mato-grossense e o Sudeste brasileiro, principalmente nas atividades ligadas à agropecuária. Evidentemente, a precariedade dos transportes da região impedia maiores vínculos e ganhos para a região. Visando superar esse gargalo foi construída a estrada de rodagem entre Campo Grande e Porto 15 de Novembro (atual Bataguassu) na divisa com São Paulo, às margens do rio Paraná, inaugurada em 1890 e reinaugurada³ em 1905 (Queiroz, 2008; Le Bourlegat, 2000). Posteriormente, a obra de maior relevância na integração entre o SMT e a região Sudeste foi justamente a NOB, que originalmente tinha como trajeto Bauru-Cuiabá. Porém, em 1907, o Decreto

3 Depois de uma tentativa fracassada, ainda na década de 1890 foi finalmente entregue ao tráfego público em 1905 (Queiroz, 2008, p. 53). 
estadual $n^{\circ} 200$ estabeleceu Corumbá como ponto final da ferrovia (Le Bourlegat, 2000).

Nesse período observa-se que os projetos voltados para a integração de MT e de sua porção sul (SMT), em geral, eram apenas pontuais no sentido de que buscavam atender demandas de escoamento da produção local e/ou facilitar a comercialização dos produtos provenientes do Sudeste. Esses projetos foram insuficientes para dinamizar o crescimento e promover o desenvolvimento econômico da região. A realidade econômica local começa a ser alterada somente a partir do Estado Novo de Getúlio Vargas, com a perspectiva nacional-desenvolvimentista de planejamento do desenvolvimento regional (Abreu, 2001; Le Bourlegat, 2000; Albanez, 2013).

Para entender essa mudança a partir do Estado Novo é importante ressaltar que, após a Guerra do Paraguai, surge a Companhia Matte Larangeira, ${ }^{4}$ responsável pela maior parte da extração e produção da erva-mate que se expande na porção Sul de Mato Grosso (SMT). A companhia controlava milhões de hectares de terras devolutas arrendadas pelo Estado (Albanez, 2013) e teve importante papel no desenvolvimento da região.

A presença e atuação dessa companhia é uma das principais razões que justificam as primeiras políticas ativas (projetos, investimentos e ações amplas) de desenvolvimento regional em MS (ainda Mato Grosso). Em outras palavras, Vargas compreendia que o domínio das terras pela Matte Larangeira no SMT era um empecilho para a política desenvolvimentista. ${ }^{5}$ Sendo assim, ele utilizou de sua força política para enfraquecer a companhia.

Mais especificamente, em 1943 criou-se o Território Federal de Ponta Porã e a Colônia Agrícola de Dourados (CAND). A criação do território federal ressaltava o problema da concentração da posse das terras pela Matte Larangeira e pelas oligarquias agrárias da região. A criação da CAND, por sua vez, faz parte de um processo de colonização baseado na pequena propriedade que teve início durante o Estado Novo. O objetivo era promover a diversificação da produção nacional, alicerçada ao desenvolvimento industrial brasileiro.

\section{4 "Larangeira" faz referência ao nome de Thomaz Larangeira.}

5 Vale lembrar que Getúlio Vargas rompe com a predominância do pensamento liberal que havia no Brasil até a década de 1920. No que se refere às questões regionais, "Vargas teve a sensibilidade política e econômica de transformar em 'nacionais' vários outros problemas 'regionais', colocando-os sob a gestão e o apoio da agenda do governo federal” (Cano, 2008, p. 7). 
As colônias agrícolas tinham por finalidade "receber e fixar, como proprietários rurais, cidadãos brasileiros reconhecidamente pobres que revelassem aptidão para os trabalhos agrícolas e, excepcionalmente, agricultores qualificados estrangeiros", sendo que "todas as despesas decorrentes da fundação, instalação e manutenção das colônias, inclusive construção e conservação das vias principais de acesso" seriam custeadas pela União, nos limites dos créditos destinados a esse fim (Brasil, 1941). Apesar de terem sido criadas 12 Colônias Agrícolas Nacionais, a CAND foi a que alcançou maior êxito, servindo inclusive de "propaganda" como "colônia modelo" (Vietta, 2013, p. 47-48).

Segundo Oliveira (2013), desde o ano de 1923, já havia uma área de 50 mil hectares, no SMT, destinada à colonização (Lei estadual n ${ }^{\circ} 616$, de 20 de janeiro de 1923). Entretanto, ao usar da sua influência econômica política, a empresa Mate Laranjeira conseguia interferir nesse processo, direcionando as áreas sobre as quais os migrantes deveriam se fixar, de preferência onde não existissem os ervais.

A Colônia agregou à região uma pauta produtiva diversificada e permitiu a consolidação do setor do agronegócio, contribuindo para a expansão da atividade agrícola em MT (Abreu, 2001; Rivas, 2016; Oliveira, 2013). Entre as culturas produzidas, destacaram-se o cultivo do algodão; arroz; milho; feijão e a mandioca.

Constituía objetivo dessa política, também, transformar a CAND em um centro urbano. A partir dessa experiência teve início o surgimento de cidades na porção do extremo sul de MT. ${ }^{6}$ A venda ilícita de terras, a marginalização e a violência contra os povos indígenas foram aspectos negativos dessa experiência (Vietta, 2013; Abreu, 2001).

Em resumo, segundo Queiroz (2008, p. 58):

Nesse contexto se inserem, portanto, diversas medidas estadonovistas no sentido de enfraquecer a referida Companhia, como, por exemplo, a recusa em renovar suas vastas concessões ervateiras, a imposição de taxas sobre a erva cancheada e o apoio de produtores independentes da empresa, com a criação do Instituto Nacional do Mate e de cooperativas de produtores. Em 1943, o governo chegou a transformar em territórios federais as áreas de atuação da Companhia, no SMT e no oeste do estado do Paraná - respectivamente o território de Ponta Porã $e$ de Iguaçu. Dentre todas essas medidas destaca-se ainda, em fins de 1943, a Colônia Agrícola de Dourados (CAND) - a qual, locada em áreas até então adjudicadas à Companhia Matte Larangeira, deveria contribuir para a ocupação dos chamados "espaços vazios" do oeste brasileiro.

6 A partir da CAND fundaram-se as bases para o surgimento de municípios de Dourados, Douradina, Fátima do Sul, Jateí, Glória de Dourados e Deodápolis (Vietta, 2013, p. 48). 
A partir dos estudos supracitados evidencia-se que tanto a criação do Território Federal de Ponta Porã como a CAND constituíram-se em iniciativas que impulsionaram o desenvolvimento da região.

\subsection{A criação da SUDECO e os seus programas de desenvolvimento}

Ainda que durante o programa "Marcha para o Oeste" tenham sido criados órgãos responsáveis pela promoção do desenvolvimento das regiões, como o Instituto Nacional do Mate e da Concessão de Terras na Fronteira (CTFF), é possível afirmar que o protagonismo dos organismos estatais na condução do planejamento e execução do desenvolvimento regional ascendeu a partir da experiência das Superintendências de Desenvolvimento. A Superintendência de Desenvolvimento do Nordeste (SUDENE) foi pioneira e serviu como referência para as demais.

Segundo Cano (1981), não foram apenas as questões nordestinas que desencadearam a criação de instituições de apoio regional. Com a divulgação das Contas Nacionais do Brasil, em 1951 e 1952 (a partir de dados coletados desde 1939), identificaram-se elevados investimentos industriais e em infraestrutura no centro-sul do país (principalmente em São Paulo) em detrimento de outras regiões, que passaram a exercer pressões políticas "reclamando, para elas, tratamento prioritário de desenvolvimento" (Cano, 1981, p. 6). Como resultado, surgiram novas políticas e instituições de desenvolvimento regional fora do Nordeste (Cano, 1981; Diniz, 2009).

É nesse contexto político e histórico que foi criada, em 1961, a Comissão de Desenvolvimento do Centro Oeste (CODECO), transformada em 1967 na SUDECO. Essa superintendência, vinculada ao Ministério do Interior, atuava nos territórios de Goiás, Mato Grosso (ainda não desmembrado) e no Território Federal de Rondônia. Ela incorporou à época a Fundação Brasil Central, herdando seu patrimônio e alguns dos seus serviços, como a administração de escolas e hospitais. No entanto, o cerne da competência da SUDECO era a realização de programas, pesquisas e levantamentos que apresentassem e desenvolvessem o potencial econômico da Região, embasando ações planejadas a curto e a longo prazo (Brasil, 1967).

Inicialmente a superintendência ficou responsável por gerir alguns programas na região Centro-Oeste, entre as quais o Programa de Desenvolvimento do Centro-Oeste (PRODOESTE), dentro do contexto do I Programa 
Nacional de Desenvolvimento. O Programa visava incrementar o desenvolvimento econômico do sul dos estados de Mato Grosso, Goiás e do Distrito Federal (Brasil, 1971).

Mais especificamente, o PRODOESTE buscava ampliar a rede rodoviária regional, proporcionando "ligação adequada dessas áreas (Centro-Oeste) aos principais centros de consumo, industrialização e exportação, implantando, para isso, eficiente sistema viário" (IPEA, 1971, p. 8) e, assim, "propiciar a circulação tanto de mercadorias quanto de pessoas" (Rivas, 2016, p. 147) (Figura 1 no Anexo).

Para contemplar a proposta do programa o governo "despendeu os valores de Cr\$213,4 milhões (US\$36.009.571,26) em 1972 e Cr\$386,8 milhões (US\$ 63.202.048) em 1973" (Abreu, 2001, p. 85). Embora uma parte significativa dos recursos tenha sido investida em silos, armazéns, usinas e frigoríficos, além de obras de saneamento e recuperação de terras, a maior parte dos investimentos foram direcionados para a infraestrutura rodoviária. No território do atual estado de MS os trechos rodoviários prioritários foram: a) BR-163 trecho Rondonópolis (MT)-Campo Grande-Dourados (MS); BR-262 - trecho Campo Grande-Aquidauana-Corumbá (MS); e, b) BR-376 trecho Dourados (MS)-Paranavaí (PR) (Brasil, 1971).

Acerca dos resultados, é possível observar que o programa possibilitou o asfaltamento da rodovia que liga MT a SP e a pavimentação de $1.988 \mathrm{~km}$ de novas rodovias e $2.849 \mathrm{~km}$ de recuperação (apesar de os números serem controversos), além da implantação ou de melhorias de vias (Abreu, 2001; Rivas, 2016). Le Boulegat (2000) aponta que a partir da ampliação das redes de transportes e comunicação com o Sudeste, principalmente com São Paulo, houve ganhos de produtividade e da própria produção agrícola da região sul-mato-grossense.

Ademais, o PRODOESTE serviu de referência para que a SUDECO elaborasse o seu primeiro Plano de Desenvolvimento Econômico e Social para o Centro-Oeste (PLADESCO) (Le Boulegat, 2000). Esse plano deriva do diagnóstico da própria instituição referente à reduzida participação do Centro-Oeste no produto nacional. Assim, foram estabelecidas metas numéricas como "elevar a participação do setor da indústria na formação do Produto Regional Bruto, de 5,5\% (1968) para 10\%, até o fim do período considerado (fim da década de 1970)" (SUDECO, 1973, p. 83). E, também, aumentar o coeficiente médio de utilização da força de trabalho na região em $50 \%$ até o fim da década de 1970, uma vez que foi diagnosticado que 
somente $45 \%$ da população entre 10 e 59 anos era economicamente ativa (SUDECO, 1973).

Especificamente em MS, o PLADESCO buscou promover o aperfeiçoamento da pecuária e expandir as lavouras mecanizadas de trigo e soja, bem como o processamento desses produtos (Figura 2 do Anexo). Segundo Abreu (2001) e Terra (2006), o principal mecanismo para concretizar os objetivos do plano eram os investimentos em infraestrutura (energia, transporte, urbanização, armazenagem). Inseridas nesse contexto, foram contempladas duas áreas: o eixo Campo Grande-Dourados e a área de Corumbá (SUDECO, 1973). As diretrizes do plano para a primeira região incluíram: a) tecnificação da produção; b) industrialização da produção; e, c) desenvolvimento urbano. Para a região de Corumbá a programação incluía maior atenção para a tecnificação da pecuária e a industrialização da carne.

Entre os resultados destacam-se a fixação da população e o desenvolvimento urbano, a tecnificação da agropecuária e a industrialização da produção, além da incorporação de novas áreas de produção. Dessa forma, o PLADESCO "organizou no Centro-Oeste um avanço do capital, firmado na ideia de planejamento enquanto ação racional, global, sistemática (...)" (Abreu, 2001, p. 91).

Posteriormente, no território de MS destacam-se os "programas especiais", entre os quais o PRODEPAN, o POLOCENTRO e o PRODEGRAN.? $O$ primeiro abrangeu a região pantaneira, sendo que a maior parte dos recursos foi destinada para a construção da rodovia Transpantaneira. Favoreceram-se, também, investimentos no desenvolvimento da pecuária. O programa não logrou tanto sucesso, uma vez que vários projetos ficaram inacabados, executados de forma incompleta ou mesmo sequer iniciados (Abreu, 2001, Kmitta, 2013).

Por sua vez, o POLOCENTRO abrangeu duas áreas: o eixo Campo Grande-Três Lagoas e a região de Bodoquena (ver Figura 3 no Anexo). Na primeira, concentrou seus investimentos em armazenamento, energia e transportes, num total de Cr\$402.230.000,00 (US\$ 4.334.000,00) no período de 1975 a 1981 (Abreu, 2001). Inclui o financiamento de instalações de

7 Existem outras ações públicas em prol do desenvolvimento durante o período. Um exemplo é o Programa Nacional para as Cidades de Porte Médio (PNCPM), desenvolvido nas cidades de Campo Grande, Dourados, Corumbá e Três Lagoas. O Programa foi implementado no âmbito do II Plano Nacional de Desenvolvimento (II PND 1975-1979) e tinha como objetivo principal transformar as referidas cidades em polos de desenvolvimento, a partir de investimentos setoriais e da implantação de distritos industriais. Ver Souza, Abreu e Vieira (2015). 
armazéns (Campo Grande, Ribas do Rio Pardo, Três Lagoas e Brasilândia) e Silos (Campo Grande); o melhoramento de trechos da rodovia BR-262 entre Campo Grande e Três Lagoas e dos trechos entre Três Lagoas e Bataguassu da rodovia MT 428, além de financiamento para criação de estradas rurais e redes de energia (SUDECO, 1975). Esses investimentos buscavam atender e aprimorar as atividades da agroindústria e pecuária na macrorregião de Campo Grande e da mineração de calcário na região de Bodoquena (Le Boulegat, 2000).

Por fim, o mais exitoso dos programas, o PRODEGRAN, tinha como área de atuação a região da Grande Dourados. O programa buscou estimular a vocação agrícola da região: a) expandido a fronteira agrícola; b) criando incentivos ao aumento da produtividade; c) utilizando práticas conservacionistas d) introduzindo novas culturas; e) modernizando suas práticas de comercialização; e, f) criando e fortalecendo sua agroindústria (SUDECO, 1979). Constituíam objetivo também melhorar e ampliar a infraestrutura regional de energia, transporte e armazenamento (Pereira, 2013).

Destaca-se no âmbito desse programa o apoio técnico e financeiro recebido da Embrapa, do governo do estado de Mato Grosso e dos próprios municípios, que em conjunto despenderam um total de Cr\$664 milhões, direcionados principalmente aos setores de energia, transportes e armazenamento. Segundo Abreu (2001), a região da Grande Dourados, entre 1975 e 1978, era responsável por 46\% de toda a produção das principais culturas de MS e 43\% da área plantada no estado.

A criação do estado de MS corroborou para o sucesso do programa, como aponta o relatório da SUDECO (1977, p. 26):

A resposta aos estímulos governamentais, através do PRODEGRAN e da cria-
ção do Estado de Mato Grosso do Sul, foi imediata e surpreendente. Conse-
quentemente, as necessidades daquela região ampliaram-se de tal forma que
o encerramento do programa tornou-se temerário, sem que antes o Governo lhe
tenha propiciado um tal estágio de desenvolvimento que seria, por si só, o indutor
para sua autossustentação.

O diagnóstico apresentado pela superintendência converge com a análise de Silva (2011), que aponta para uma transformação produtiva da região-alvo do programa. Em termos quantitativos houve um significativo crescimento no uso de fertilizantes $(2.200 \%)$ e na utilização de máquinas e equipamentos (tratores, colheitadeiras e arado mecânico). Isso demonstra a modernização da produção viabilizada pelos incentivos, financiamentos e subsídios estatais. 


\section{0 encerramento das superintendências e as novas diretrizes das políticas de desenvolvimento regional}

\subsection{0 "fim" da SUDECO e o início das políticas de "incentivos fiscais"}

A SUDECO influenciou positivamente o desenvolvimento regional de MS e do Centro-Oeste. Contudo, sua influência foi limitada e restrita no tempo. Em grande parte, isso pode ser explicado pelo fato de que as ações da superintendência dependiam do capital estrangeiro. Organismos internacionais como o Banco Internacional para Reconstrução e Desenvolvimento e o Fundo Monetário Internacional, além dos bancos privados estadunidenses, financiaram grande parte dos programas dessa superintendência e dos projetos de desenvolvimento do regime militar (correspondendo aos interesses e dinamismos da Guerra Fria) (Araújo, 2010; Abreu, 2001).

Por outro lado, a crise internacional do petróleo e a crise do endividamento público associadas a baixas taxas de crescimento colocaram em xeque o modelo de desenvolvimento nacional. A elevação dos gastos com os programas de desenvolvimento passou a ser questionada.

Ressalta-se, ainda, uma mudança em termos de pensamento econômico no contexto latino-americano do final da década de 1970, com a ascensão da hegemonia neoliberal. Dessa forma, nos anos seguintes "houve um completo desmonte do aparato governamental relacionado ao planejamento, em que sucumbiram também as instituições que haviam sido construídas com a finalidade de reduzir as desigualdades regionais" (Cargnin, 2014, p. 85).

Aplicado à SUDECO, esse contexto indicava a fragilidade do modelo de planejamento, o que posteriormente acarretou no seu esvaziamento e na sua extinção em 1990. Segundo Abrita e Silva (2017), a falta de autonomia financeira, a escassez de recursos e a incapacidade da Superintendência em responder aos anseios do capital industrial são fatores que explicam a sua decadência.

Constata-se que entre 1985-1995 não houve a implementação (sob o ponto de vista dos estudos de desenvolvimento regional brasileiro) de políticas expressivas de desenvolvimento regional. Nesse período foi promulgada a Constituição de 1988 que, em seu artigo 159, instituiu os Fundos Constitucionais de Financiamento. Entre esses se destaca o Fundo Constitucional de Financiamento do Centro-Oeste (FCO). 
Segundo Cintra (2007) esses fundos foram criados mais para compensar a fragilidade financeira e fiscal dos estados e municípios do que de uma perspectiva de desenvolvimento regional. Essa fragilidade desencadeou a chamada "guerra fiscal". Ou seja, as unidades federativas passaram a conceder incentivos fiscais, especialmente manipulando as alíquotas do Imposto sobre Circulação de Mercadorias e Serviços (ICMS) para atrair investimentos (Prado, 1999; Nascimento, 2008; Macedo, 2013).

A "guerra fiscal" consiste em uma "forma peculiar de políticas de desenvolvimento regional” (Prado, 1999, p. 7). Macedo (2013) indica que essas políticas ganharam relevância no Brasil no final do século XX com a perda de força do Estado Nacional e seu enfraquecimento diante da globalização, o que levou os entes da federação a agirem de forma concorrencial para atrair os capitais que, por sua vez, buscavam novas localizações territoriais. ${ }^{8}$

A competição tributária horizontal ocorre entre entes governamentais de mesmo nível hierárquico. No caso brasileiro, ocorre entre unidades federativas, especialmente via isenção do ICMS; ou entre municípios, via isenções do Imposto sobre Serviços (ISS), do Imposto Predial e Territorial Urbano (IPTU), da doação ou cessão de terrenos, entre outros. Segundo a Pesquisa de Informações Básicas Municipais (2015), divulgada pelo Instituto Brasileiro de Geografia e Estatística (IBGE), a prática de conceder incentivos fiscais para atrair empresas está bem disseminada pelos municípios brasileiros. Segundo a pesquisa, em 2015, 61,7\% (3.437) dos municípios utilizavam esses mecanismos, enquanto em 2012, 62,9\% (3.498).

Em termos estaduais, a avaliação mais aprofundada dos impactos dessas políticas de incentivos fiscais fica comprometida pela falta de dados adequados, como o cálculo da matriz insumo-produto. Nascimento (2008) usou o modelo econométrico de "Diferenças em Diferenças" para avaliar as alterações entre os estados e entre os períodos anterior e posterior à guerra fiscal, 1990-1996 e 1997-2005, respectivamente, nas seguintes variáveis: a) receitas do Imposto Sobre Circulação de Mercadorias e Serviços (ICMS); b) geração de novos postos de trabalho na indústria de transformação; e, c) PIB por setor. Para tanto, o autor compara o estado de São Paulo, que foi "menos agressivo" na guerra fiscal, com os estados participantes da disputa fiscal: Paraná, Rio Grande do Sul, Rio de Janeiro, Ceará, Bahia,

8 Para uma discussão sobre os efeitos dessas políticas em outros países ver, por exemplo, Peter e Fischer (2004) para os Estados Unidos; Bondonio e Greenbaum (2007) para a Itália; e Jenkins e Chun-Yan Kuo (2007) para Taiwan, entre outros. 
Minas Gerais, Espírito Santo, Goiás, Mato Grosso, Mato Grosso do Sul e Santa Catarina. Os resultados mostram que houve alterações significativas na taxa de crescimento da participação estadual no PIB industrial do país, em comparação ao estado paulista, no segundo período.

Nesse contexto, o estado de MS é tido como participante ativo da guerra fiscal (Nascimento, 2008; Dulci, 2002). Além das linhas de créditos tradicionais (BNDES Automático, FINAME e Programa de Geração de Renda-PROGER) e da linha de fomento empresarial constituída pelo FCO, em termos estaduais a política de incentivos fiscais pode ser encontrada, por exemplo, no Programa MS-EMPREENDEDOR. Esse programa dispõe sobre benefícios ou incentivos fiscais concedidos às indústrias que se instalarem ou ampliarem suas instalações.

Segundo dados do IBGE (2015), entre os 79 municípios do estado, 71 tinham mecanismos de incentivo à implantação de empreendimentos $(89,9 \%)$. A Tabela 1 mostra os tipos de incentivos utilizados por municípios de MS.

Tabela 1 Tipos de incentivos fiscais por município em MS (2015)

\begin{tabular}{lr}
\hline Mecanismo de incentivo utilizado & Quantidade de municípios \\
\hline Redução do IPTU & 39 \\
\hline Isenção do IPTU & 38 \\
\hline Isenção do Imposto sobre serviços & 38 \\
de qualquer natureza (ISSQN) & 34 \\
\hline Isenção de taxas & 35 \\
\hline Cessão de terrenos & 56 \\
\hline Doação de terrenos & 23 \\
\hline Outros & 36 \\
\hline
\end{tabular}

Fonte: Paz; Zamberlan; Lamberti (2017).

Em 2014, segundo Ribeiro Silva (2016), 121 indústrias receberam incentivos fiscais do estado de MS. Ainda, segundo o autor, grande parte dos empreendimentos são originários de São Paulo (36 dos 49 identificados), de modo que "a proximidade com o estado de São Paulo fundamenta uma estrutura produtiva sul-mato-grossense com uma considerável interferência da atmosfera industrial paulista" (2016, p. 138). Isso é particularmente verdadeiro no município de Três Lagoas. A partir dos incentivos fiscais desenvolveu-se nesse município um polo de crescimento (nos moldes de 
Perroux), principalmente a partir do setor de celulose, uma vez que algumas indústrias motrizes (Fibria, Eldorado, International Paper) impulsionaram a chegada de outras indústrias e empresas motoras no município. Segundo dados do Cadastro Central de Empresas do IBGE, o número de empresas locais passou de 2.500 para 3.500 entre 2006 e 2016 (IBGE, 2016). Evidentemente, Três Lagoas também se beneficiou da localização estratégica e da infraestrutura energética instalada nas proximidades (Missio et al. 2019).

Novamente, uma avaliação mais detalhada dos efeitos desses incentivos depende da construção de exercícios analíticos elaborados e de bases de dados mais completas (que fogem ao escopo deste trabalho). Não obstante, baseados em Nascimento (2008), testamos a presença de quebras estruturais nas variáveis analisadas pelo autor. Mais especificamente, estamos interessados em identificar a presença de mudanças nas trajetórias das séries que possam mostrar que a política de incentivos fiscais (guerra fiscal), que se acirrou no final dos anos de 1990, teve efeitos sobre a estrutura produtiva sul-mato-grossense. Os resultados mostram que, em relação à evolução do PIB industrial em MS, não foi possível identificar mudanças repentinas nas séries no período analisado, enquanto o teste para a variável "número de admissões na indústria de transformação" indicou a presença de quebras estruturais no período analisado. ${ }^{9}$

\subsection{Os eixos nacionais de integração de desenvolvimento (ENIDs)}

A Constituição de 1988 estabeleceu que os programas de duração continuada deveriam constar nos planos plurianuais. ${ }^{10}$ Dessa forma, segundo Freitas (2012), a retomada do planejamento do desenvolvimento regional na pauta governamental ressurge a partir do Plano Plurianual (PPA) do quadriênio 1996/1999. ${ }^{11}$ Nesse plano previam-se o aproveitamento das poten-

9 Os testes podem ser solicitados aos autores por e-mail.

10 Art. $165 \$ 1^{\circ}$ A lei que instituiu o plano plurianual estabelecerá, de forma regionalizada, as diretrizes, objetivos e metas da administração pública federal para as despesas de capital e outras delas decorrentes e para as relativas aos programas de duração continuada (Brasil, 1988).

11 Essa "retomada" ocorre de forma completamente diferente das fases passadas em que predominava a visão teórico-prática do desenvolvimentismo. Ou seja, em um contexto de endividamento do Estado nacional e da inserção das políticas neoliberais do Consenso de Washington, predomina agora a preocupação com a estabilização da economia e a adoção da 
cialidades regionais a partir do uso racional e sustentável dos seus recursos e o fortalecimento da base de infraestrutura das regiões menos desenvolvidas e da política de desconcentração industrial (Brasil, 1996). Assim, com base nas diretrizes e orçamentos do plano e nas propostas apresentadas no governo Fernando Henrique Cardoso, foi lançado em agosto de 1996 o "Programa Brasil em Ação".

O programa "Brasil em ação" tinha como objetivo gerenciar e organizar com eficácia a utilização dos recursos públicos (Brasil, 1996b). Os projetos eram voltados para a integração nacional. Deu-se início à política dos "Eixos Nacionais de Integração e Desenvolvimento".

Os programas são desenhados, preferencialmente, buscando eixos de desenvolvimento, que é a concepção moderna do desenvolvimento. Não se trata de um polo de desenvolvimento que concentre numa região, mas de um eixo que distribua seus efeitos numa área mais ampla, pois é necessário que o Governo preste atenção ao conjunto do Brasil (Brasil, 19966, p. 13).

O programa "Brasil em Ação" contou com um total de 42 empreendimentos, dos quais 16 eram voltados para a área social e 26 para a área de infraestrutura. Em um recorte voltado para o MS, percebe-se que três foram as políticas programadas para melhorar a infraestrutura de transportes, são elas: a) Recuperação das BR-364/163; b) Construção da estrada de ferro Ferronorte; e c) Conclusão da hidrovia Tietê-Paraná. O objetivo principal desses projetos era escoar a produção da região. Havia, ainda, o projeto que envolvia a implementação do Gasoduto Brasil-Bolívia, pois teria a cidade de Corumbá como uma das pontas do gasoduto brasileiro (Brasil, 1998).

Destaca-se, também, o Programa de Desenvolvimento Sustentável do Pantanal (PROGRAMA PANTANAL), que inclui projetos voltados para a "melhoria de vida da população" (redes de água e saneamento básico) e gerenciamento dos recursos naturais (florestas, cobertura vegetal, bacias hidrográficas) (Abreu, 2001).

As políticas de Eixos do "Brasil em Ação" foram avaliadas como positivas pelo Governo Federal. Na campanha de reeleição de Fernando Henrique Cardoso, foi lançado o programa "Avança Brasil". ${ }^{12}$ Confirmada a cartilha das reformas neoliberais. Ver Gumiero (2017).

12 Segundo Abreu (2008), o programa pressupunha o entendimento de que a competitividade da economia nacional era prejudicada por fatores "sistêmicos" ("Custo Brasil"). Nesse caso, buscou-se privilegiar os investimentos em infraestrutura econômica. São exemplos de políticas a quebra de monopólios de empresas estatais e mudanças na regulamentação dos setores de energia, telecomunicações, petróleo e portos. 
reeleição, esse programa transformou-se no Plano Plurianual 2000/2003, onde aprofundaram-se as ideias e diretrizes dessa política.

Chama atenção o fato de que esse plano foi elaborado com base nos serviços de consultoria (por licitação), realizados em 1997, que resultou na formação do Consórcio Brasiliana, formado pelas firmas Booz Allen \& Hamilton do Brasil Consultores, Betchel International Incorporation e Banco ABN Amro, sob a supervisão das equipes do BNDES e do Ministério do Planejamento. O consórcio elaborou os Estudos Nacionais de Integração e Desenvolvimento. O objetivo inicial era identificar as oportunidades de investimentos públicos e/ou privados nos setores essenciais para o desenvolvimento econômico e social nas zonas de influência dos Eixos ${ }^{13}$ (Nasser, 2000; Tavares, 2016).

Em resumo, a política de Eixos tinha como preocupação reduzir as desigualdades regionais, pois considerava que o desenvolvimento sustentável exigia o crescimento integrado de todas as regiões, sendo para isso necessário que a distribuição regional dos recursos fosse diretamente proporcional ao grau de carência de cada região. Então, criou-se um portfólio de investimentos públicos e privados dentro dos Eixos Nacionais de Integração e Desenvolvimento. Muitos desses investimentos acabaram contemplados no PPA 2000/2003 (Brasil, 2000).

Apesar da existência de outros projetos, o cerne dessa política em MS era o de dar continuidade aos projetos previstos no PPA anterior e, portanto, envolvia a construção da Ferronorte e do gasoduto Brasil-Bolívia e a construção da hidrovia Tietê-Paraná.

A Ferrovia opera desde 2008 sobre o nome de América Latina Logística Malha Norte S.A, por concessão deliberada da Agência Nacional de Transportes Terrestres (ANTT), com atuação em MT e MS, somando 500 $\mathrm{km}$ de extensão de linha (ANTT, 2008). Quanto à sua operacionalidade, Souza (2008) destaca que no ano de 2001 a ferrovia já transportava 30\% da produção de soja e farelo de MT e MS, num percurso de $1.300 \mathrm{~km}$ entre Alto Taquari (MT) e o porto de Santos (SP), em quatro trens com 42 vagões cada um. Todavia, essa operacionalidade atendia, sobretudo, os interesses de companhias agroindustriais, em especial empresas multinacionais como Cargill, ADM e Bunge, que já tinham na época terminais

13 A Secretaria Especial de Políticas Regionais (Sepre), vinculada ao Ministério do Planejamento e Orçamento, contratou a organização e formulação do Plano de Desenvolvimento Sustentável para a região Centro-Oeste (Planoeste) (Gumiero, 2017). 
ferroviários, ao mesmo tempo que detinham $60 \%$ da safra brasileira de soja $^{14}$ (Souza, 2008).

O gasoduto Brasil-Bolívia (inaugurado em fevereiro de 1999) aumentou consideravelmente a oferta de energia, favorecendo a implantação industrial. Por exemplo, o gasoduto favorece o desenvolvimento da indústria mineradora em Corumbá. Segundo Lamoso (2001), a possibilidade de exploração do minério e a exportação do produto com beneficiamento primário antecede a Segunda Guerra Mundial. Contudo, a verticalização da atividade, com a implantação de um polo siderúrgico, precisava do fornecimento de energia em maior volume e com garantia de regularidade, o que só se tornou possível a partir da construção do referido gasoduto.

A hidrovia Paraná-Tietê representa importante rota de escoamento dos produtos de MS, transportando mais de 9 milhões de toneladas na navegação interior (ANTAQ, 2017).

Observa-se, assim, que o objetivo da política dos "Eixos" em MS era aumentar as vantagens competitivas da matriz produtiva já estabelecida (agroexportadora). Isso fica claro no desenvolvimento dos projetos de infraestrutura envolvendo a hidrovia Paraná-Tietê e a Ferronorte. Ao fortalecerem apenas determinadas regiões, é possível argumentar que essas políticas reforçaram as desigualdades regionais no estado.

Por fim, cumpre ressaltar que nesse período (anos 2000) foram criados também fundos estaduais com o objetivo de promover o desenvolvimento, a saber: a) Fundo de Desenvolvimento do Sistema Rodoviário de Mato Grosso do Sul (FUNDERSUL), que visava criar uma nova fonte de recursos para manter e viabilizar estradas e pontes estaduais; e b) Fundo de Investimento Social (FIS), com o objetivo principal de financiar as ações de inclusão social no estado (Reis Neto, 2000).

\subsection{Política nacional de desenvolvimento regional (PNDR) e outras práticas}

A partir de 2003, esboçou-se uma retomada das ações direcionadas para combater as desigualdades regionais e sociais (Gumiero, 2017). Algumas

14 Uma das críticas à ferrovia sustenta que o projeto tende a atender interesse do capital privado, dos grandes agricultores e em grande medida do Grupo Itamarati e de grupos internacionais. 
ações corroboram essa afirmação: a reativação da SUDENE, da SUDECO e da Superintendência do Desenvolvimento da Amazônia (SUDAM); a reorientação do Fundo Constitucional de Financiamento (FNO, FNE e FCO) e dos Fundos de Desenvolvimento Regional (FDA e FDNE), a promoção de programas mesorregionais pelo Governo Federal (PROMESO, CONVIVER, PDFF, PDSA) inseridos nos Planos Plurianuais (PPAs) de 2004-2007 e de 2008-2011 e, principalmente, a institucionalização, em 2007, da Política Nacional de Desenvolvimento Regional (PNDR).

A PNDR formulou três planos macrorregionais, incluindo o Plano Estratégico de Desenvolvimento do Centro-Oeste (PDCO), com investimentos previstos de $\mathrm{R} \$ 147,34$ bilhões de reais entre 2007 e 2010. Ademais, foram elegidas as sub-regiões consideradas estratégicas e prioritárias para as quais foi formulado o Programa de Desenvolvimento da Faixa de Fronteira (PDFF) (SEMAC, 2012).

Outros dois programas merecem destaque. O primeiro refere-se ao Programa de Investimento em Logística (PIL), lançado pelo Governo Federal em 2012. Estavam previstos projetos e investimentos no setor rodoviário, ferroviário, portuário e aeroportuário em MS. Contudo, somente os projetos referentes às concessões rodoviárias foram materializados, mais especificamente a concessão da BR-163/MS (Fernandes, 2018).

O segundo refere-se ao Programa de Aceleração do Crescimento (PAC), criado em 2007 pelo Governo Federal. O Programa tinha por objetivo o fomento de ações em logística, energia e infraestrutura urbana e previa investimentos de $\mathrm{R} \$ 503,9$ bilhões. Segundo Souza e Abreu (2012), para o MS estavam previstos inicialmente investimentos de $\mathrm{R} \$ 9,5$ bilhões (Tabela 2).

Tabela 2 PAC - total investido em MS até dezembro de 2010 (milhões)

\begin{tabular}{l|r|r|r|r|r}
\hline \multirow{2}{*}{ Eixo } & \multicolumn{2}{|}{$\begin{array}{r}\text { Empreendimentos } \\
\text { exclusivos }\end{array}$} & \multicolumn{2}{|r|}{$\begin{array}{r}\text { Empreendimentos } \\
\text { de caráter regional }\end{array}$} & $\begin{array}{r}\text { Subtotal } \\
\text { (milhões) }\end{array}$ \\
\cline { 2 - 5 } & $\mathbf{2 0 0 7 - 2 0 1 0}$ & Pós 2010 & $\mathbf{2 0 1 7 - 2 0 1 0}$ & Pós 2010 & \\
\hline Logística & $1.602,9$ & 65,1 & 98,6 & 162,8 & $1.929,4$ \\
\hline Energética & $2.762,3$ & $5.250,6$ & 429,4 & 403,8 & $8.846,1$ \\
\hline Social e Urbana & $2.923,4$ & - & - & - & $2.923,4$ \\
\hline Total & $7.288,60$ & $5.315,7$ & 528,0 & 566,6 & $13.698,9$ \\
\hline
\end{tabular}

Fonte: Souza; Abreu (2012, p. 8). 
Segundo Souza e Abreu (2012), os investimentos em MS produziram mudanças na infraestrutura social e urbana. Assim, "ao contemplar parcela da população e espaços historicamente excluídos das políticas governamentais, comportou diversos avanços no sentido da integralidade, da equidade e da universalidade dos serviços de saneamento" (Souza; Abreu 2012, p. 1).

Apesar desses resultados, é possível apontar criticamente algumas incongruências nessas políticas recentes de desenvolvimento regional. Em primeiro lugar, a criação do Fundo Nacional de Desenvolvimento Regional (FNDR), prevista desde o PPA 2004-2007 e proposta posteriormente pelo projeto de Lei n ${ }^{\circ} 375 / 2015$, não prosperou. Segundo Klink (2013) e Coelho (2017) a criação do fundo foi barrada por alguns estados que preferem outras formas de transferência de recursos, ou ainda, que preferem persistir na "guerra fiscal" como mecanismo de atração de investimento.

Em segundo lugar, o PNDR, previsto no PPA 2004-2007 e incluído também no PPA 2008-2011, não incorporou instrumentos substantivos de execução e orçamento para se concretizar (Coelho, 2017). Ademais, o PAC se sobrepôs ao PNDR (Klink, 2013).

Por fim, cumpre salientar que a SUDECO foi recriada em 2009. Porém, ela mantém-se pouco atuante, conforme relatório da própria superintendência (SUDECO, 2016). O planejamento estratégico ficou a cargo de uma empresa especializada que seria contratada para a elaboração do referido plano. Restrições orçamentárias e financeiras impediram a sua concretização. A mesma dificuldade se observa quando se analisam os tópicos relacionados ao desempenho, ações e resultados obtidos pela autarquia, já que existe uma série de projetos não executados, não aprovados e com valores não empenhados.

\section{Considerações finais}

No pós-crise de 1929, o Brasil passou a adotar políticas de cunho desenvolvimentista, especialmente a partir da ascensão de Getúlio Vargas à Presidência da República. Nesse período criaram-se empresas estatais, houve maior aparelhamento do Estado e intensificou-se o processo de industrialização.

Em relação às políticas de desenvolvimento regional, inaugura-se uma nova fase, constituída por grandes programas/projetos. São exemplos o 
programa "Marcha para o Oeste" e a criação dos territórios federais, das colônias agrícolas e de instituições como a Fundação Brasil Central.

No SMT a atuação estatal pautada na colonização e no desenvolvimento ocorreu principalmente através da criação do Território Federal de Ponta Porã e da Colônia Agrícola de Dourados. Getúlio buscou diminuir a influência da Cia. Matte Larangeira, centralizando o domínio do referido território à esfera federal e negando a renovação das concessões de terras à companhia. Ao mesmo tempo, o projeto da CAND foi pautado na cessão de terras aos migrantes, bem como na construção da infraestrutura da região. Essas políticas tiveram efeitos positivos sobre a região, com o aumento da população não indígena local e a diversificação das atividades produtivas.

Destaca-se, também, o papel fundamental das superintendências de desenvolvimento. A elaboração e execução de programas de desenvolvimento por essas superintendências tiveram seu ápice durante a execução dos Planos Nacionais de Desenvolvimento (I e II PND) no regime militar. No SMT destaca-se a atuação da SUDECO. Os programas desenvolvidos por essa superintendência tinham como objetivo, entre outros, criar a infraestrutura na região e fomentar a criação de polos de crescimento. Apesar dos distintos resultados, é possível afirmar que eles ajudaram a criar polos produtivos específicos em MS, como nos casos de Corumbá, Campo Grande e Dourados.

Esse modelo de desenvolvimento se esgotou a partir das crises do petróleo na década de 1970 e do período inflacionário da década de 1980. Concomitantemente, na segunda metade dos anos de 1980 e início dos anos de 1990 houve certo abandono das políticas de desenvolvimento regional, em grande parte por influência da ascensão da ideologia (neo)liberal. Num primeiro momento, essa nova orientação econômica levou à "guerra fiscal”, onde os diferentes entes da federação passaram a usar de políticas de incentivos fiscais para atrair investimentos e instalações indústrias.

Ainda sob o escopo neoliberal, o planejamento e as políticas de desenvolvimento regional voltaram a ter relevância somente nos mandatos do presidente Fernando Henrique Cardoso. Na política dos "eixos", o objetivo principal era dar competitividade aos setores produtivos brasileiros, em especial ao setor privado, por meio de maior integração da economia nacional. Essa integração se daria a partir de investimentos em infraestrutura (modelo de "corredores"). 
Em MS, essa política tinha como principal objetivo diminuir os custos de escoamento da produção. Para tanto, promoveu-se a ampliação da infraestrutura, a construção de hidrelétricas, do gasoduto Brasil-Bolívia e da malha ferroviária.

Já dentro da política nacional de desenvolvimento, os investimentos realizados reforçaram em grande parte os objetivos dos programas anteriores, especialmente aqueles direcionados à ampliação da infraestrutura relacionada ao escoamento da produção agrícola. Nas políticas mais recentes (especialmente no PAC) é possível observar também preocupação maior com a infraestrutura social e urbana.

Como indicação para trabalhos futuros destacamos a necessidade de se avaliar a prevalência das elites e dos grandes grupos privados como beneficiários dessas políticas de desenvolvimento.

\section{Referências}

ABREU, S. Planejamento governamental: a SUDECO no espaço Mato-Grossense: contextos, propósitos e contradições. Tese (Doutorado) - Universidade de São Paulo, Faculdade de Filosofia, Letras e Ciências Humanas, São Paulo, 2001.

ABREU, S. Mato Grosso do Sul - aspectos contraditórios das políticas públicas de desenvolvimento: novas/velhas práticas. In: LAMOSO, L. P. (Org.). Transportes e políticas públicas em Mato Grosso do Sul. Dourados: Editora UFGD, v. 1, p. 117-134, 2008.

ABRITA, M. B.; SILVA, W. G. Políticas de desenvolvimento regional: uma análise a partir da atuação da primeira Superintendência de Desenvolvimento do Centro-Oeste (1967-1990). Ateliê Geográfico, v. 11, n. 1, p. 235-256, 2017.

AGÊNCIA NACIONAL DE TRANSPORTES AQUAVIÁRIOS - ANTAQ. Sistema Intermodal de Transportes Tietê-Paraná apresenta-se como o principal modelo brasileiro. Brasil, 2017. Disponível em: <http://www.portalfederativo.gov.br/noticias/destaques/sistema-intermodal-de-transporte-tiete-parana-apresenta-se-como-o-principal-modelo-brasileiro/ sistemaintermodaltieteparana_revista_web-2-02-08-2018.pdf>. Acesso em: 02 nov. 2018

ALBANEZ, J. L. Ervais em queda transformações no campo no extremo sul de Mato Grosso (19401970). Dourados: Editora UFGD, 2013.

ARAÚJO, M. A. C de. A SUDECO e seus gestores: o Estado como agente de produção na consolidação do capitalismo monopolista na Região Centro-Oeste. In: SIMPÓSIO NACIONAL ESTADO E PODER: CULTURA. VI., Núcleo de Pesquisa Estado e Poder. Universidade Federal do Sergipe, 2010. Anais...

BARCELLOS, J. Mato Grosso do Sul (1978-1979): utopia x realidade. Campo Grande: Instituto Histórico e Geográfico de Mato Grosso do Sul (IHGMS), 2014.

BONDONIO, D.; GREENBAUM, R. T. Do local tax incentives affect economic growth? 
What mean impacts miss in the analysis of enterprise zone policies. Regional Science and Urban Economics, 37, p. 121-136, 2007.

BRASIL, Decreto-Lei n ${ }^{\circ}$ 3.059, de 14 de fevereiro de 1941. Disponível em: <http://www2. camara.leg.br/legin/fed/declei/1940-1949/decreto-lei-3059-14-fevereiro-1941-413001-publicacaooriginal-1-pe.html>. Acesso em: 21 set. 2017.

BRASIL, Lei $n^{\circ} 5.365$, de $1^{\circ}$ de dezembro de 1967. Disponível em: http://www.planalto.gov. br/ccivil_03/leis/1950-1969/L5365.htm Acesso em: 21 set. 2017.

BRASIL, Decreto-Lei n ${ }^{\circ} 1.192$, de 8 de novembro de 1971. Disponível em: <http://www. planalto.gov.br/ccivil_03/decreto-lei/1965-1988/Del1192.htm>. Acesso em: 14 set. 2017.

BRASIL, Constituição da República Federativa do Brasil de 1988, de 05 de outubro de 1988. Disponível em: <http://www.planalto.gov.br/ccivil_03/Constituicao/Constituicao.htm>. Acesso em: 21 set. 2017.

BRASIL, Presidência da República - Casa Civil Subchefia para Assuntos Jurídicos. Lei $\mathrm{n}^{\circ}$ 9.276, de 9 de maio de 1996. Disponível em: <http://www.planalto.gov.br/ccivil_03/leis/ L9276.htm>. Acesso em: 14 set. 2017.

BRASIL, Presidência da República. Brasil em Ação: investimentos para o desenvolvimento. Brasília: Presidência da República, Secretaria de Comunicação Social, Ministério do Planejamento e Orçamento, 1996b.

BRASIL, Presidência da República. Programa Brasil em Ação: dois anos. Brasília: Secretaria de Comunicação Social, 1998.

BRASIL, Congresso Nacional. Plano Plurianual 2000-2003 Anexo I: Diretrizes Estratégicas e Macro-objetivos. Brasil, 2000. Disponível em: <http://www.planalto.gov.br/ccivil_03/ leis/1998-2000/anexo/ANL9989-I-00.pdf>. Acesso em: 14 set. 2017.

CANO, W. Crise e industrialização no Brasil entre 1929 e 1954: a reconstrução do Estado Nacional e a política nacional de desenvolvimento. Revista de Economia Política, v. 35, n. 3 (140), p. 444-460, 2015.

CANO, W. Desequilíbrios regionais e concentração industrial no Brasil - 1930/1970. Tese (Doutorado) - Universidade Estadual de Campinas, Departamento de Economia e Planejamento Econômico, Campinas, 1981.

CANO, W. Getúlio Vargas e a formação e integração do mercado nacional. In: ENCONTRO NACIONAL DE PÓS-GRADUAÇÃO E PESQUISA EM PLANEJAMENTO URBANO E REGIONAL (ANPUR). XI., Salvador, 2008.

CARGNIN, A. P. O sentido das políticas de desenvolvimento regional. Revista de Economia do Nordeste, Fortaleza, v. 45, n. 4, p. 83-95, 2014.

CINTRA, M. A. M. Relatório 3: Fundos Constitucionais de Financiamento (do Norte, do Nordeste e do Centro-Oeste). Unicamp, 2007. Disponível em: <http://www3.eco.unicamp. br/cecon/images/arquivos/pesquisa-2006-2007/SubprojetoIXRelat3BNDES.pdf>. Acesso em: 22 jul. 2016.

COELHO, V. L. P. A política Regional do Governo Lula (2003-2010). In: Desenvolvimento regional no Brasil: políticas, estratégias e perspectivas. MONTEIRO NETO, A.; CASTRO, C. N. de; BRANDÃO, C. A. (Org.). Rio de Janeiro: Ipea, 2017.

DINIZ, C. C. Celso Furtado e o desenvolvimento Regional. Nova Economia, n. 19, p. 227-249, 
2009.

DULCI, O. S. Guerra fiscal, desenvolvimento desigual e relações federativas no brasil. Revista de Sociologia e Política, n. 18, p. 95-107, 2002.

FERNANDES, R. M. da S. O programa de investimento em logística (PIL) em Mato Grosso do Sul: projetos e materialidade (concessão da BR-163). Revista Eletrônica da Associação dos Geógrafos Brasileiros, n. 28, ano 14, p. 104-132, 2018.

FOCHEZATTO. A. Desenvolvimento regional: novas abordagens para novos paradigmas produtivos. In: CONCEIÇÃO, O. A. C. et al. (Org.). Três décadas de economia gaúcha: o ambiente regional. Porto Alegre, RS: Fundação de Economia e Estatística, 2010. v. 1, p. $163-190$.

FOCHEZATTO, A.; VALENTINI, P. J. Economia de aglomeração e crescimento econômico regional: um estudo aplicado ao Rio Grande do Sul usando um Modelo Econométrico com Dados de Painel. EconomiA, Selecta, Brasília (DF), v. 11, n. 4, p. 243-266, 2010.

FREITAS, W. D. de. O planejamento regional brasileiro no fim do século XX os eixos nacionais de integração e desenvolvimento. Revista Territorial, Goiás, v. 1, n. 1, p. 47-72, 2012.

GUMIERO, R. G. Trajetória de políticas de desenvolvimento regional para a fronteira sul de mato grosso do sul. Revista Desenvolvimento, Fronteiras e Cidadania, v. 1, n. 1, p. 161-181, 2017.

INSTITUTO BRASILEIRO DE GEOGRAFIA E ESTATÍSTICA (IBGE), Cadastro Central de Empresas 2006; Rio de Janeiro: IBGE, 2016.

INSTITUTO DE PLANEJAMENTO ECONÔMICO E SOCIAL (IPEA). Legislação básica do PRODOESTE. Brasília, 1971.

ISARD, W. Location and Space-Economy: A General Theory Relating to Industrial Location, Market Areas, Land Use, Trade, and Urban Structure. New York, The Massachusetts Institute of Technology (MIT), 1956.

JENKINS, G. P.; KUO, Chun Yan. Evaluating the Relative Impact of Fiscal Incentives and Trade Policies on the Returns to Manufacturing in Taiwan, 1955-1995. Asian Economic Journal, v. 21, n. 1, p. 75-100, 2007.

KLINK, J. A escalaridade e a espacialidade do (novo) desenvolvimentismo: uma exploração conceitual para o debate. In: BRANDÃO, C.; SIQUEIRA, H. (Org.). Pacto federativo, integração nacional e desenvolvimento regional. São Paulo: Perseu Abramo, 2013.

KMITTA, I. do R. PRODEPAN: O Pantanal como nova fronteira econômica nacional. In: SIMPÓSIO NACIONAL DE HISTÓRIA - ANPUH, XXVII., Natal, 2013.

LAMOSO, L. P. A exploração de minério de ferro no Brasil e no Mato Grosso do Sul. Tese (Doutorado) - Universidade de São Paulo, Faculdade de Filosofia, Letras e Ciências Humanas, São Paulo, 2001.

LE BOURLEGAT, C. A. Mato Grosso do Sul e Campo Grande: articulações espaços-temporais. Tese (Doutorado) - Universidade Estadual Paulista, Faculdade de Ciências e Tecnologia, Presidente Prudente, 2000.

LIMA, A. C. C.; SIMÕES, R. F. Teorias do Desenvolvimento Regional e suas Implicações de Política Econômica no pós-guerra: o Caso do Brasil. Belo Horizonte: UFMG/CEDEPLAR, 2009. 33 p. 
LOSCH, A. The economics of location, 1940. Massachusetts, Yale University Press, Seventh printing: 1978.

MACEDO, F. C. de; ANGELIS, Â. de. Guerra fiscal dos portos e desenvolvimento regional no Brasil. Redes (St. Cruz Sul, On-line), v. 18, n. 1, p. 185-212, 2013.

MINISTÉRIO DA INDÚSTRIA, COMÉRCIO EXTERIOR E SERVIÇOS - MDIC. Importações Brasileiras por Fator Agregado - Estado: Mato Grosso do Sul. Brasília, 2018. Disponível em: <http://www.mdic.gov.br/balanca/comex-vis/uf/output/html/ms.html>. Acesso em: 22 out. 2018.

MISSIO, F.; SONAGLIO, C. M.; FERREIRA, B. M. O. B. Notas sobre as etapas de desenvolvimento de Três Lagoas (MS): um exercício Rostowiano. Geosul, v. 34, p. 156-194, 2019.

MISSIO, F. J.; RIVAS, R. M. R. Aspectos da formação econômica de Mato Grosso do Sul. Estudos Econômicos [on-line], v. 49, n. 3, p. 601-632, 2019.

NASSER, B. Economia Regional, Desigualdade Regional no Brasil e o Estudo dos Eixos Nacionais de Integração e Desenvolvimento. Revista do BNDES, v. 7, n. 14, p. 145-178, 2000.

NASCIMENTO, S. P. Guerra fiscal: uma avaliação comparativa entre alguns estados participantes. Economia Aplicada, v. 12, n. 4, p. 677-706, 2008.

OLIVEIRA, B. C. Colônia Agrícola Nacional de Dourados: a marca de Vargas na Marcha para Oeste, In: MARIN, J. O. B; NEVES, D. P. (Org.). Campesinato e Marcha para Oeste. Santa Maria: Editora da UFSM, 2013.

PAZ, P. P.; ZAMBERLAN, C. O.; LAMBERTI, E. Industrialização e incentivos fiscais: uma discussão sobre a experiência do estado de Mato Grosso do Sul. In: SEMINÁRIO INTERNACIONAL SOBRE TERRITÓRIOS, REDES E DESENVOLVIMENTO REGIONAL: PERSPECTIVAS E DESAFIOS. VIII., Santa Cruz do Sul/ RS, 2017. Anais...

PEREIRA, J. dos S. A presença dos incentivos governamentais na economia douradense: expansão e desafios nos anos 70.123 f. Dissertação (Mestrado em História) - Universidade Federal da Grande Dourados (UFGD), Dourados-MS, 2013.

PRADO, S. Guerra fiscal e políticas de desenvolvimento regional no Brasil. Revista Economia e Sociedade, Campinas, 13, p. 1-40, 1999.

PROGRAMA DAS NAÇÕES UNIDAS PARA O DESENVOLVIMENTO (PNUD). Atlas do Desenvolvimento Humano no Brasil - Mato Grosso do Sul. Brasil, 2013. Disponível em: $<$ http://www.atlasbrasil.org.br/2013/pt/perfil_uf/50>. Acesso em: 19 out. 2018

QUEIROZ, P. R. C. A navegação na bacia do Paraná e a integração do antigo sul de Mato Grosso ao mercado nacional. Revista História Econômica \& História de Empresas, VII.1, p. 165-197, 2004.

QUEIROZ, P. R. C. Articulações econômicas e vias de comunicação do antigo sul de Mato Grosso (século XIX e XX). In: LAMOSO, L. P. (Org.). Transportes e políticas públicas em Mato Grosso do Sul. Dourados: Editora UFGD, 2008.

QUEIROZ, P. R. C. "Caminhos e fronteiras": vias de transporte no extremo oeste do Brasil. In: GOULART FILHO, A.; QUEIROZ, P. R. C. (Org.) Transportes e formação regional: contribuições à história dos transportes no Brasil. Dourados: Editora UFGD, 2011.

REIS NETO, J. F. dos. Planos de Desenvolvimento do Estado de Mato Grosso do Sul: investigação dos seus atributos relevantes. Dissertação (Mestrado) - Universidade Federal do Rio 
Grande do Sul, Escola de Administração, Porto Alegre: UFGRS/PPGA, 2000.

RIBEIRO SILVA, C. H. Política industrial brasileira e a industrialização de Mato Grosso do Sul no século XXI. 2016. 277 f. Tese (Doutorado em Geografia) - Faculdade de Ciências Humanas da Universidade Federal da Grande Dourados (UFGD), Dourados-MS, 2016.

RIVAS, R. M. R. Ensaios da formação histórica, política e econômica do estado de Mato Grosso do Sul. Dissertação (Mestrado) - Universidade Estadual de Mato Grosso do Sul - Programa de Pós Graduação em Desenvolvimento Regional e Sistemas Produtivos (PPGDRS), Ponta Porã, 2016.

SECRETARIA DE ESTADO DE MEIO AMBIENTE, DO PLANEJAMENTO, DA CIÊNCIA E TECNOLOGIA - SEMAC. Plano de Desenvolvimento e Integração da Faixa de Fronteira do Estado de Mato Grosso do Sul (PDIF/MS), 2012.

SILVA, W. G. A integração produtiva da região da Grande Dourados à economia nacional: Uma análise a partir da criação do Prodegran em 1976. In: II Conferência do Desenvolvimento, 2011, Brasília. Anais do I Circuito de Debates Acadêmicos da II Conferência de Desenvolvimento. Brasília: IPEA, 2011. p. 01-15.

SOUZA, A. de O. Mato Grosso do Sul no contexto dos novos paradigmas de integração e desenvolvimento nacional. Dourados: Editora UFGD, 2008.

SOUZA, A. de O.; ABREU, S. De; VIEIRA, A. B. Política e Desenvolvimento Espacial Urbano - Análise do Processo de Implantação do Programa Nacional de Cidades de Porte Médio em Mato Grosso do Sul. Formação (on-line), v. 2, p. 43-58, 2015.

SOUZA, A. de O.; ABREU, S. de. Política, planejamento e território: aspectos da inserção do Estado de Mato Grosso do Sul no Programa de Aceleração do Crescimento (PAC) 2007-2010. In: SEMINÁRIO INTERNACIONAL ESTADO, TERRITÓRIO E DESENVOLVIMENTO: CONTRADIÇÕES, DESAFIOS E PERSPECTIVAS, Salvador/Bahia, 2012. Anais...

SOUZA, N. J. de. Economia regional: conceitos e fundamentos teóricos. Perspectiva Econômica Universidade do Vale do Rio dos Sinos, ano XVI, v.11, n. 32, p. 67-102, 1981.

SUPERINTENDÊNCIA DO DESENVOLVIMENTO DA REGIÃO CENTRO-OESTE (SUDECO). Programa de desenvolvimento dos cerrados - POLOCENTRO; documento base; plano de ação 1975/1977. Brasília, 1975.

SUPERINTENDÊNCIA DO DESENVOLVIMENTO DA REGIÃO CENTRO-OESTE -(SUDECO). PLADESCO - Plano de Desenvolvimento Econômico-Social do Centro-Oeste. Brasília, 1973.

SUPERINTENDÊNCIA DO DESENVOLVIMENTO DA REGIÃO CENTRO-OESTE (SUDECO). PRODEGRAN: Relatório Final 1976/1978. Brasília, 1979.

SUPERINTENDÊNCIA DO DESENVOLVIMENTO DA REGIÃO CENTRO-OESTE (SUDECO). Relatório de Gestão do Exercício de 2015. Brasília, 2016.

TERRA, A. A modernização agropecuária de Mato Grosso do Sul: 1970-1985. In: ENCONTRO DE GRUPOS DE PESQUISA UNIVERSIDADE FEDERAL DE UBERLÂNDIA. II., Uberlândia-MG, 2006.

TAVARES, J. C. Eixos: novo paradigma do planejamento regional? Os eixos de infraestrutura nos PPAs nacionais, na Iirsa e na macrometrópole paulista. Caderno Metropolitano de São 
Paulo, v. 18, n. 37, p. 671-695, 2016.

VIETTA, K. Histórias territoriais: a privatização das terras Kaiowa como estratégia para a guarnição da fronteira brasileira e outras histórias. Espaço Amerindio, Porto Alegre, v. 7, n. 2, p. 26-63, 2013.

VON THUNEN, J. H. The Isolated State. Hamburg: Perthes, 1826. English translation. Oxford: Pergamon, 1966.

WEBER, A. Theory of the location of industries. Chicago: Chicago University, 1909.

\section{Sobre os autores}

Kaully Furiama Santos - kaullyf.s@gmail.com

Faculdade de Sinop (Fasip). Sinop, MT, Brasil.

ORCID: https://orcid.org/0000-0003-2496-9142.

FabricioJ.Missio-fjmissio@cedeplar.ufmg.br

Universidade Federal de Minas Gerais, Centro de Desenvolvimento e Planejamento Regional, Belo Horizonte, MG, Brasil. ORCID: https://orcid.org/0000-0003-4561-6039.

\section{Sobre o artigo}

Recebido em 19 de fevereiro de 2019. Aprovado em 12 de fevereiro de 2020. 


\section{APÊNDICE}

Figura 1 PRODOESTE - Rede rodoviária básica de Mato Grosso

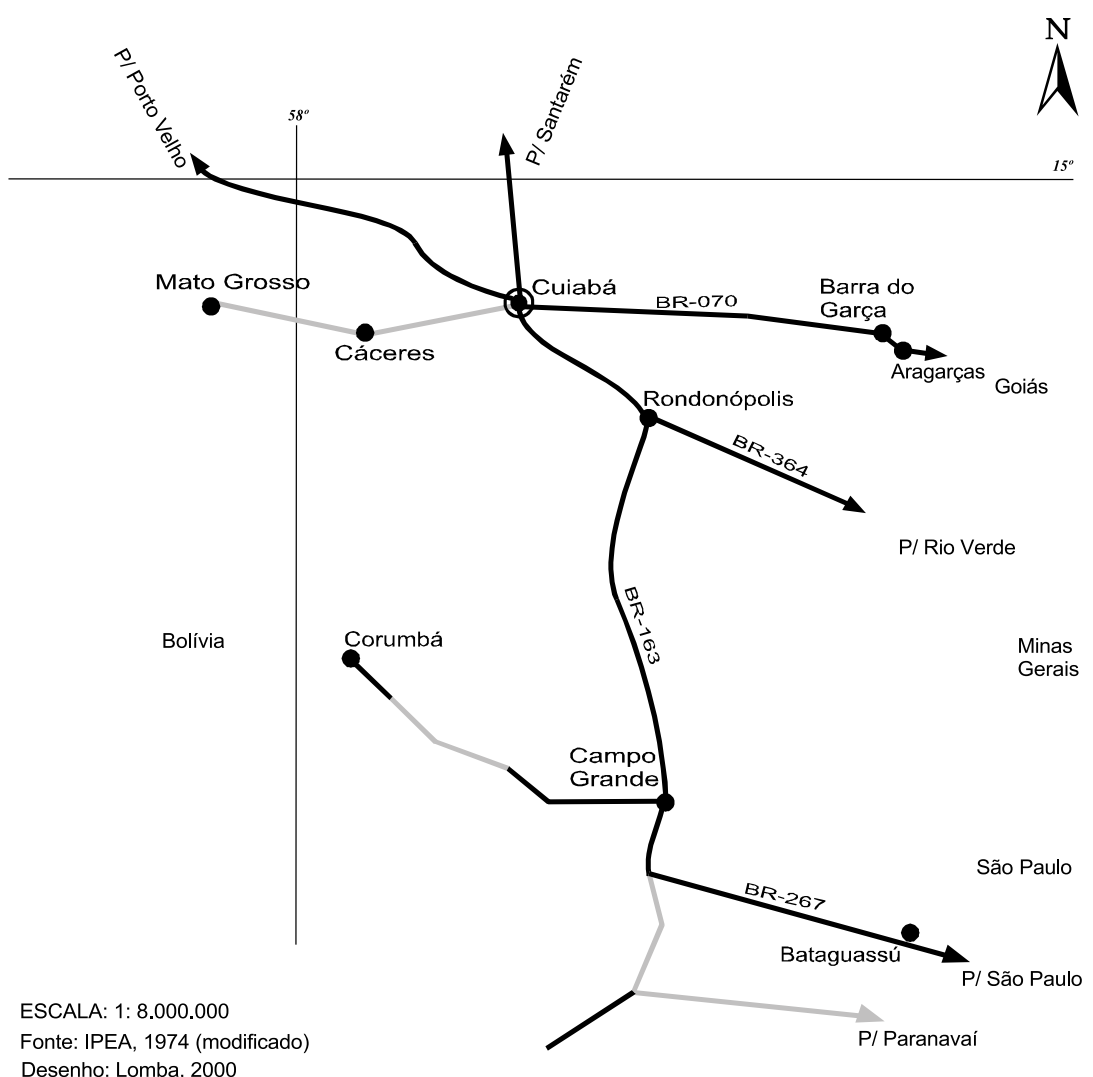

Desenho: Lomba, 2000

Paraguai

Paraná

Rodovias existentes

Rodovias em construção

Fonte: Abreu (2001).

A figura apresenta os objetivos do PRODOESTE no que se refere a construção/melhorias das rodovias. Destacam-se no SMT os seguintes trechos: BR-163 - Trecho Rondonópolis (MT) - Campo Grande - Dourados (MS); BR-262 - Trecho Campo Grande - Aquidauana - Corumbá; e BR-376 Trecho Dourados-Paranavaí (Brasil, 1971, Art. $2^{\circ}, \mathbb{\$} 1^{\circ}$ ). 
Figura 2 I PLADESCO - áreas selecionadas

ESCALA: 1:14.635.000

Fonte: MINTER/SUDECO, 1973a

Desenho: Lomba, 2000

Organização: Abreu, 2000

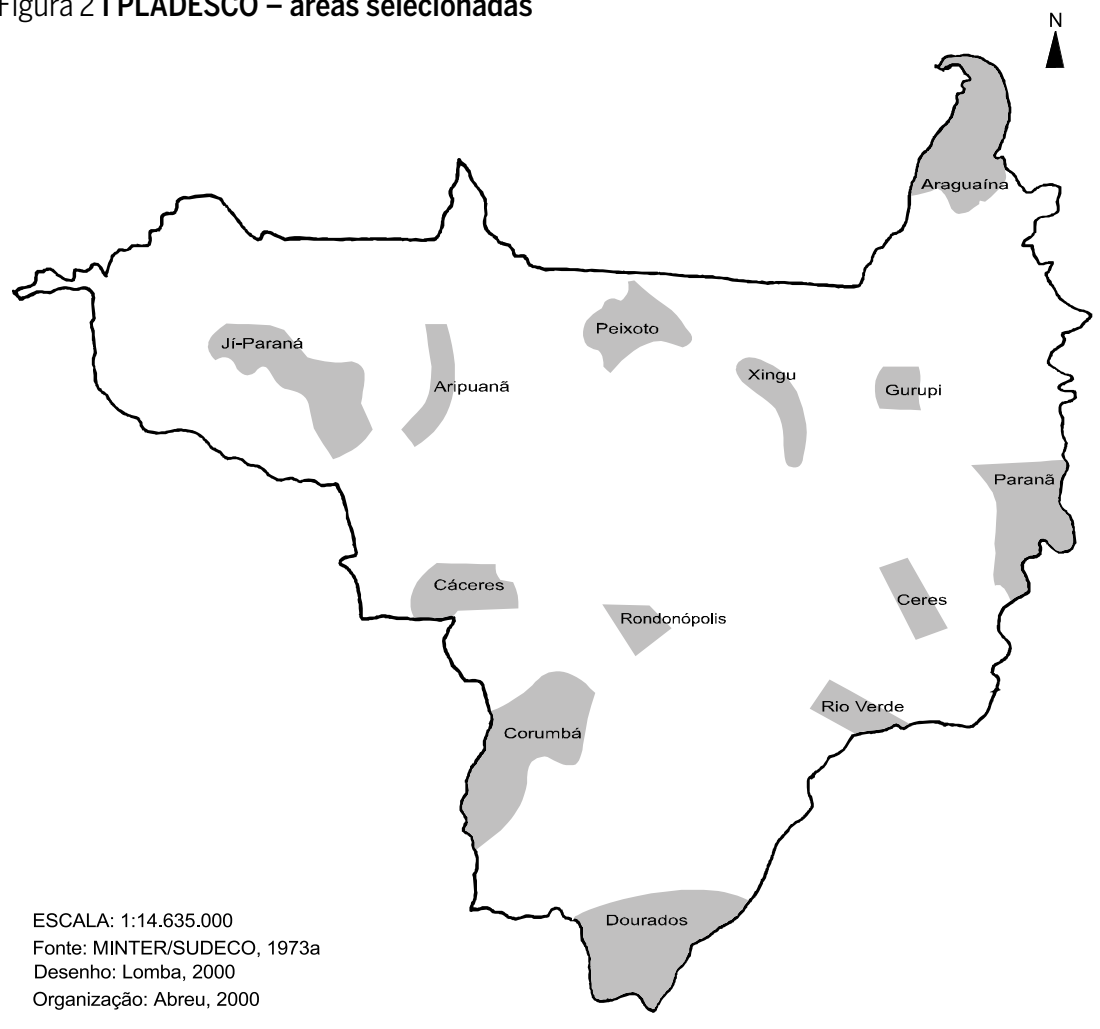

Fonte: Abreu (2001).

Observam-se nessa figura as denominadas "treze áreas-programas" que eram prioridades do PLADESCO e que concentravam a maior parte dos recursos. Cumpre ressaltar as áreas-programas localizadas na região SMT. 
Figura 3 POLOCENTRO - Campo Grande-Três Lagoas e Bodoquena

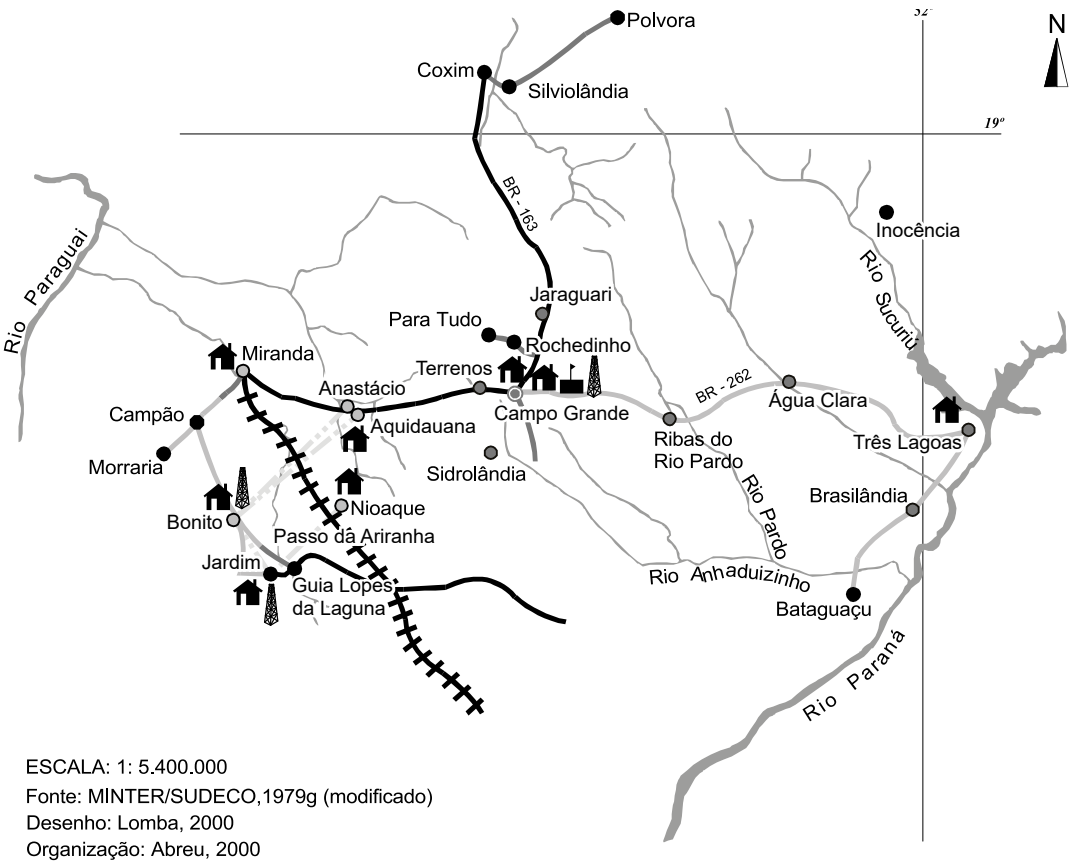

Programação transporte
O Áreas prioritárias - Bodoquena
O Áreas prioritárias - Campo Grande / Três Lagoas
1 Unidade de Pesquisa
I Armazém programado

- Existente

Programação transporte
Subestação programada
Rede de transmissão

Fonte: Abreu (2001).

A figura apresenta um panorama do programa POLOCENTRO com os dois eixos de atuação prioritária: a área da Bodoquena e o eixo Campo Grande - Três Lagoas. 